International Journal of Physical Research, $9(1)(2021) 60-67$
International Journal of Physical Research
SPC
Website: www.sciencepubco.com/index.php/IJPR
Research paper

\title{
Seasonal rainfall variability and its correlation with potential drivers over Western Oromia
}

\author{
Kefiyalew Ayele Alandu ${ }^{1 *}$, Tadesse Terefe Zeleke ${ }^{2}$, Mesfin Asfaw Afrassa ${ }^{3}$ \\ ${ }^{1}$ National Meteorological Agency, SNNPR Meteorological Service Center, Hawassa, Ethiopia \\ ${ }^{2}$ Institute of Geophysics, Space Science and Astronomy (IGSSA), Addis Ababa University, Addis Ababa, Ethiopia \\ ${ }^{3}$ Department of Physics, Adama Science and Technology University, Adama, Ethiopia \\ *Corresponding author E-mail: akefiyalew@gmail.com
}

\begin{abstract}
Characterizing seasonal rainfall and identifying its association with the climate drivers are important to produce reliable seasonal climate forecasts of a given area. This study examined the rainfall variability and its relationships with SST, SLP and sunspot indices by statistical methods over Western Oromia. The regional is characterized by monomodal pattern of $60 \%$ seasonal rainfall contribution in Kiremt season. High temporal anomaly rainfall but no extremes were observed from 1981-2017. An insignificant decreasing Kiremt and Belg but, an increasing Bega trend was observed. ENSO and PDO/ DMI and AMO showed negative/ positive correlation with kiremt rainfall. ENSO, DMI and AMO showed positive correlation for belg rainfall whereas, PDO showed associated negatively for the most parts of the region. PSI to kiremt/Belg rainfall correlation showed significant positive/Negative spatial association over the western part (West Wolega and Illubabor) / the East part (Jimma \& East wollega) of the region. The results showed that there is decreasing trends in rainfall anomalies for main rainy seasons of region and good correlations these various indices. Therefore, it is suggested that seasonal climate predictions may consider these large-scale determinants oscillation indices like AMO and PDO in predicting climatic events.
\end{abstract}

Keywords: Climate Change; Climate Variability; Rainfall Anomaly; SST; SLP; Sunspot.

\section{Introduction}

Climate events that observed in the most parts of Africa are increasing and consistent with expectation from different forces (Friederike et al., 2018). Mainly it is influenced by the large scale (Atmosphere ocean) oscillations (Samuel, 2017; Fahey, 2017; Daniel, 2019). Seas surface temperature (SST) and Sea level Pressure (SLP) are the most important widely applying signals in predicting climate variables and modeling climate (Golian, 2015. On the earth, the primary factor that drives weather and climate is variation in solar irradiance which directly impacts the climate system and climate variability (Fahey, 2017). Thus, it is necessary to study ocean- atmospheric circulation dynamics and interactions for the better understanding the impact on rainfall.

Several climate studies over East Africa examined the link of Belg and Kiremt rainfall with phase of El Niño Southern Oscillation(ENSO) (Diro, 2019; Daniel, 2019; and segele,2009), Indian Ocean Dipole(IOD) (Shanko,1998), and North Atlantic Oscillation(NAO) as major drivers of regional intraseasonal rainfall variability. These regional studies pointed out ENSO and IOD have dominant influences on the climate and rainfall pattern in East africa (Daniel, 2019). Above/below average Kiremt/Summer rainfall over large parts of Ethiopia mostly coincides with strong cold/warm phases of ENSO and positive/negative IOD years (Daniel, 2019; Shanko, 1998). The Belg rainfall is negatively correlated with NAO over much of the eastern southern Ethiopia (Endalkachew, 2015).

However, few studies have been done and still there is gap of understanding regarding the influence of other indices like Atlantic Multidecadal Ocsillation(AMO) North Atlantic Oscillation (NAO) and Pacific Decadal Oscillation (PDO) and Sunspot index (PSI) on seaasonal rainfall climate over regional scale(Segele,2009;Degefu, 2017; Shanko,1998; Diro, 2011 and Gissila, 2004). In addition, the complexity in Ethiopian rainfall character that change markedly in amount over short distances is the results of the over all of various factors ranging from large scale to more regional elements(Levizzani,20018; Degefu, 2017; Shanko,1998; Diro, 2011 and Gissila, 2004). This rainfall variability induces significant social, economic and environmental impacts and considerable challenge in the world mainly in developing countries (Bezu, 2020). Therefore, this study was to investigate the rainfall variability and its association with some significant natural potential drivers by using statistical methods Over Western Oromia in the period (1981-2017. The find may contribute for understanding the rainfall climate; provide valuable information in providing reliable weather and climate forecasts for users that minimize the impacts of climate events in the region.

\section{Data and method}

\subsection{Study area and data}


West Oromia is found in the Southwestern part of Ethiopia. It is located between $7.2^{\circ}$ to $10.5^{\circ} \mathrm{N}$ and $38.2^{\circ}$ to $34.2^{\circ}$ E. The ecology of the study area is dominated by forest and fruits while the farming system is mixed farming system. The study area is characterized by the short dry and the wet season with over nine moths wet period (Daba, 2018), as seen in Figure1.

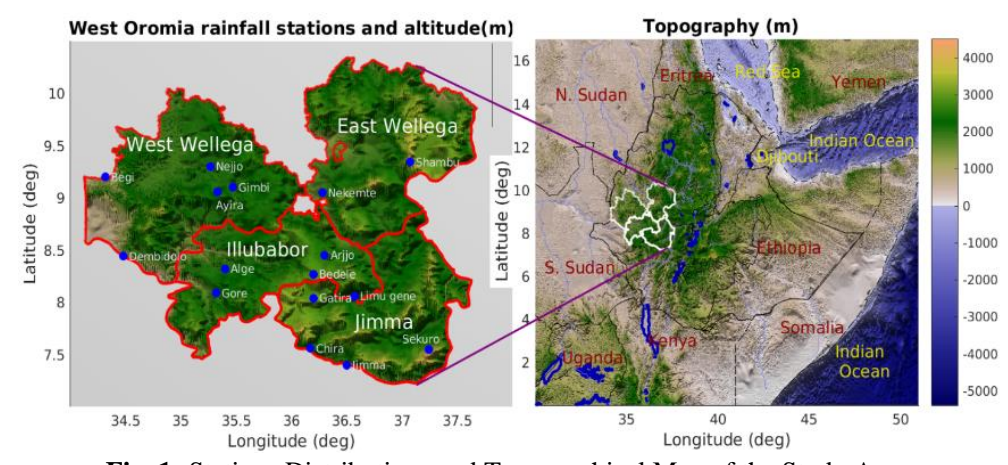

Fig. 1: Stations Distributions and Topographical Map of the Study Area.

\subsection{Data}

Rainfall datasets of 13 stations and gridded data were acquired from National Meteorological Agency (NMA) Western Oromia Meteorological Service Center for the period 1981-2017. Ocean-atmosphere oscillation indices of SST and SLP indices data were obtained from National Oceanic and Atmospheric administration (NOAA) http://www.cgd.ucar.edu.cas/catalog/climind/TNI_N34index.html ),

As large scale potential drivers, different atmospheric and oceanic indices are used to measure the effect rainfall.

a) Atmospheric pressure at sea level, i.e., sea level pressure (SLP)

1) The Southern Oscillation index (SOI) is defined as the normalized pressure difference between Tahiti, French Polynesia and Darwin, Australia.

2) The North Pacific Index (NPI) is the area-weighted SLP over the region $30-65 \circ \mathrm{N}, 160 \circ \mathrm{E}-140 \circ \mathrm{W}$.

3) The trans-polar index (TPI) is defined as the normalized pressure difference between Hobart, Australia and Stanley, Falkland Islands.

4) The North Atlantic Oscillation (NAO) is anomaly in SLP between the Icelandic LP system at SW Iceland (Reykjavik), and HP system of Azores.

5) Arctic Oscillation (AO) is sea level pressure anomalies pole ward of $20^{\circ} \mathrm{N}$, which is key aspect of climate variability in the $\mathrm{NH}$.

b) The global monthly SST anomalies

1) The Dipole mode index (DMI) or Indian Ocean dipole (IOD), defined as the difference in sea surface temperature anomaly between the western $\left(10^{\circ} \mathrm{S}-10^{\circ} \mathrm{N}, 50^{\circ}-70^{\circ} \mathrm{E}\right)$ and eastern $\left(10^{\circ} \mathrm{S}-0^{\circ}, 90^{\circ}-110^{\circ} \mathrm{E}\right)$ tropical Indian Ocean.

2) The Atlantic Multidecadal Oscillation (AMO) index is usually defined from the patterns of SST variability in the North Atlantic assuming that the effect of global forcing over the North Atlantic is similar to the global ocean, subtracted the global $\left(60^{\circ} \mathrm{N}-60^{\circ} \mathrm{S}\right)$ mean SST from the North Atlantic SST.

3) Area averaged Niño SST indices for the tropical Pacific regions described by Niño $3\left(90-150^{0} \mathrm{~W}\right.$ and $\left.5^{0} \mathrm{~N}-5^{0} \mathrm{~S}\right)$, Niño 3.4 (120$170^{\circ} \mathrm{W}$ and $\left.5^{0} \mathrm{~N}-5^{0} \mathrm{~S}\right)$, and Niño $4\left(150^{\circ} \mathrm{W}-160^{\circ} \mathrm{E}\right.$ and $\left.5^{0} \mathrm{~N}-5^{\circ} \mathrm{S}\right)$. Some ocean-atmospheric state which are an indicators of certain climate variables and climate drivers.

c) Sunspot index (PSI)

Sunspot is any of the dark spots (patches) appear at times on the sun's surface and are usually visible by telescope. It is known as photometric Sunspot index (PSI) and developed to study the effects of sunspot on solar irradiance.

\subsection{Method of analysis}

Fluctuations in rainfall

The governing equation for determining these fluctuations is known by standardized anomaly index (RAI) and given by:

$$
\mathrm{X}=\frac{\chi_{i}-\mu}{\sigma},
$$

Where,

$\mathrm{X}=$ standardized anomaly index, xi seasonal/ annual rainfall for season/ year í, $\boldsymbol{\mu}=$ mean seasonal/annual rainfall and $\boldsymbol{\sigma}=$ standard deviation of rainfall. RAI will be generated and positive/ negative anomalies have their values classified as follows: 0 to 2 humid, 2 to 4 very humid, $>4$ extremely humid -2 to 0 dry -4 to -2 very dry and <-4 extreme dry (Egor et al, 2015).

Method of Trend Analysis.

Non-parametric methods (Mann-Kendall test and Sen's slope estimator) were used to detect trends using XLSTAT software. The statistics is given as:

$S=\sum_{i=1}^{n-1} \sum_{j=i+1}^{n} \operatorname{sgn}(x j-x i)$

Where, $S$ is the Mann-Kendall's test; $x i$ and $x j$ are the sequential rainfall values in the year $i$ and $j(j>i)$, and $n$ is the length of the time series. The Sgn (xj-xi) is an indicator function, where $\mathrm{j}>\mathrm{I}$, calculated as: 
$x j-x i=\left\{\begin{array}{cll}+1 & \text { if } & x j-x i>0 \\ 0 & \text { if } & x j-x i=0 \\ -1 & \text { if } & x j-x i<0\end{array}\right\}$

The variance $(\operatorname{Var}(\mathrm{s}))$ of S-statistics in the $\mathrm{x}$ values, is given by: $\operatorname{var}(s)=\frac{1}{18}\left(-1-\sum_{i=1}^{m} t i(t i-1)(2 t i+5)\right.$. Where m is the number of tied groups in the data set and it is the number of data points in the $\mathrm{i}^{\text {th }}$ tied group. For the sample size $\mathrm{n} \geq 10$, the standard test $\mathrm{Z}_{\mathrm{mk}}$ is calculated as:

$Z m k=\left\{\begin{array}{c}\frac{s-1}{\sqrt{\operatorname{Var}(s)}} \text { if } s>0 \\ 0 \text { if } s=0 \\ \frac{s+1}{\sqrt{\operatorname{var}(s)}} \text { if } s<0\end{array}\right.$

$\mathrm{Z}_{\mathrm{mk}}$ is used to evaluate the trend. Positive $\mathrm{Z}_{\mathrm{MK}}$ indicate increasing trends, negative $\mathrm{Z}_{\mathrm{MK}}$ values reflect decreasing trends. The presence of a statistically significant trend is evaluated using the $Z_{M K}$ value. $Z_{1-\alpha / 2}$ is the critical value of $Z_{M K}$. For $5 \%$ and $10 \%$ significance level, the value of Z1- $\alpha / 2$ is 1.96 and 1.64 respectively. It is not affected by missing data, insensitivity to extreme values and better performance even for normally distributed data. Then, the slope (change per unit time) was calculated as:

$Q=\frac{X j-X i}{i-j}, i \neq j$

Where, $X_{i}$ and $X_{j}$ are data values at times $i$ and $j(j>i)$, respectively. The median of these $n$ values of $Q$ is Sen's estimator of slope (Wagesho, 2013). The correlation method used in Rainfall Correlation with SST, SLP and PSI. The monthly rainfall anomalies and the SSTs were used for identifying relationships. The correlation method using in the study was Pearson's correlation coefficient (r) which was calculated by equation:

$r=\frac{\sum_{i=1}^{n}\left(x_{i-} x_{\mu}\right)\left(y_{i}-y_{\mu}\right)}{\sqrt{\sum_{i=1}^{n}\left(x_{i}-x_{\mu}\right)^{2}\left(y_{i}-y_{\mu}\right)^{2}}}$

Where $r=$ Pearson's correlation coefficient; $x_{i}$ and $y_{i}$ were the values of SST, SLP and PSI and rainfall respectively at the time $i$; ( $x_{\mu}$ ) and $\left(\mathrm{y}_{\mu}\right)$ was the average of the SST, SLP and PSI and rainfall; and $\mathrm{n}$ was the total number of year. The t-test for the statistical significant calculated as the equation: $t=\frac{r \sqrt{n-2}}{\sqrt{1-T^{2}}}$. The $t(n-1), 0.5$ was considered for determination significant of $r$ values by comparison with the critical value at $\mathrm{t}(\mathrm{n}-1), 0.5$.

\section{Results and discussion}

\subsection{Seasonal spatial distribution, contribution and monthly rainfall for west Oromia}

Rainfall exhibited variation in spatial distribution over seasons in the study area. Kiremt (JJAS) is main rainy season for the western Oromia contributes $66 \%$ of annual rainfall in the region (figure 2). Belg (FMAM) and Bega (ONDJ) seasonal rainfall appeared to be high over southward from east and west Illubabor and Jimma zones up to $22 \%$ and $12 \%$ of the annual rainfall (Figure 2a-c), respectively. The area is characterized by monomodal rainfall pattern obtain it highest rainfall in the months July and August in Kiremt season and DJF are the driest season (months) of the region.

a) FMAM (Belg)

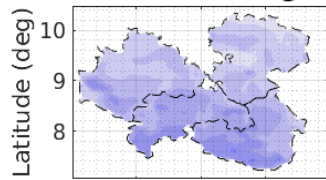

b) JJAS (kiremt)

c) ONDJ (bega)

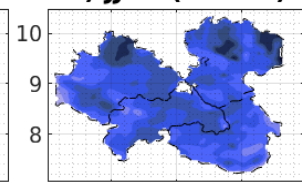

d) ${ }^{35}{ }^{36} \mathbf{M}^{3}$ (spring)
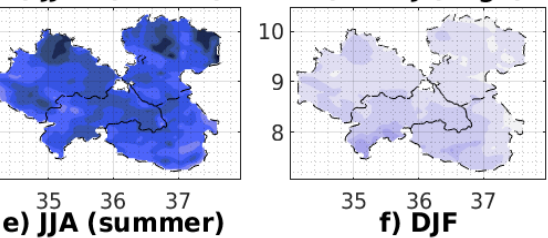

35 f) ${ }^{36} \mathbf{J} F$
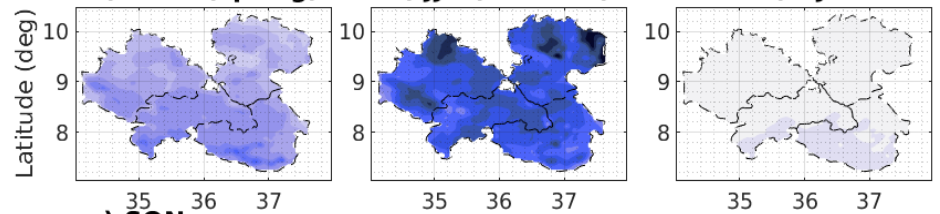

g) SON

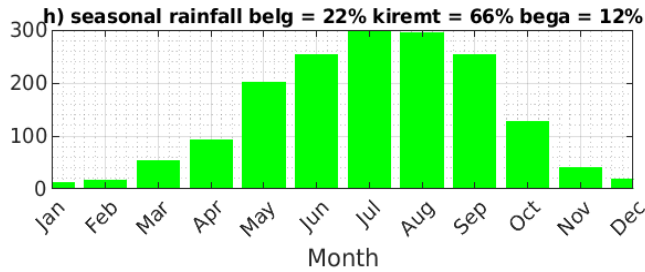

Fig. 2: Seasonal Spatial Distribution from a to g, Contribution and Monthly Rainfall Grid Data for West Oromia (1981 To2017). 


\subsection{The Seasonal rainfall anomalies in the period of 1981-2017}

The seasonal rainfall standardized anomaly (SAI) shows high inter-seasonal variability in the study area for the study period. As it can be depicted in the figure 3, weighted areal average seasonal rainfall anomalies reveled cyclic pattern of variations with alternating dry and wet seasons than the climatologically conditions years between 1981 and 2017. There were temporal variations in rainfall anomalies. When we evaluate intensity of the RAI, very dry anomaly of Kiremt/Summer 1995, 2015 and 2016 were observed. The only Belg/spring 2014 was extremely humid in the period of study and one very humid Bega 1989were seen in the historical series. In general, near normal to mild positive/negative (-2.0 to 2.0) conditions were dominated, the year 1984 is the driest and 1993 is the wettest years of the period, when all three seasons of year are wet/dry, respectively. As observed from figure 3, 1981, 1996, 2014 and 2016 are among strong negative IOD years with drier than normal Kiremt conditions were noticed. Similarly, strong El Nino years:1982-83, 1986-87, 1994-95, 1997-98, 2009-10 and 2015-16 are connected with less Kiremt rainfall than average in the region. This lined with the findings of Viste (2012) mentioned as the drought year of Ethiopia. From the trend lines of the kiremt (JJAS/JJA) and Belg (FMAM/MAM) rainfall, decreasing trend were observed. In contrary, the Bega (SON/ONDJ) season has showed an insignificantly increasing seasonal rainfall trend. In similar with this finding, Gissila et al. (2004) and Shanko (1998) revealed that there is a close link between ENSO (El Niño and La Niña) phenomena, IOD phase which is identified as potential factor for alternative wet and dry years. The spatial patterns of seasonal rainfall anomaly indices' trends show an increasing trends for the most areas of the region for MAM, SON and annual time series, whereas spatial decreasing trends for the most parts for DJF time.

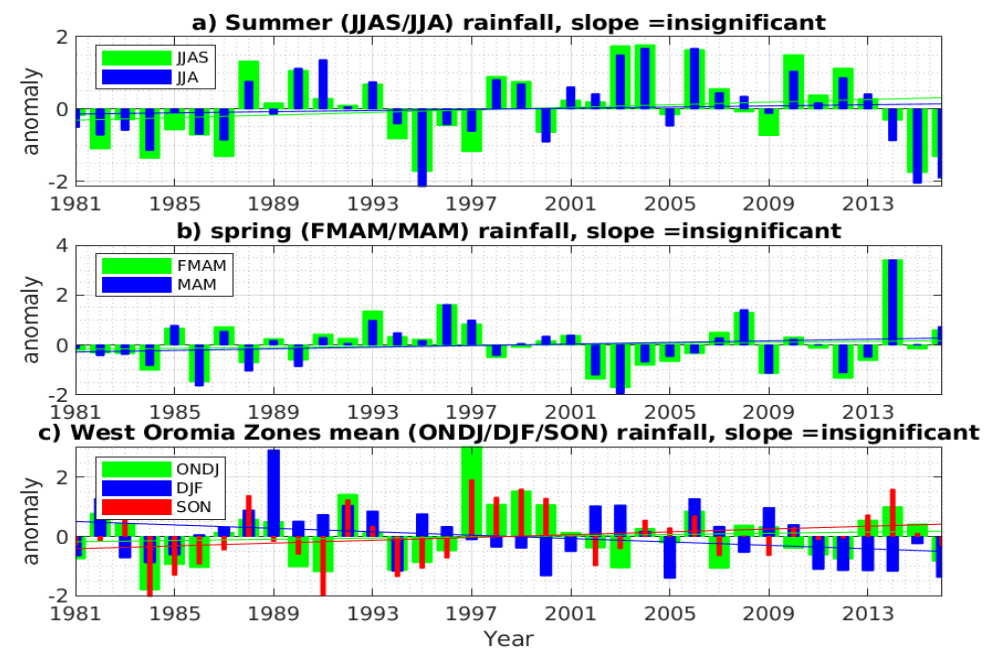

Fig. 3: Time Series Seasonal Rainfall Anomalies: The indices are a) the Kiremr/Summer (JJAS/JJA) b) Belg/spring (FMAM/MAM) and c) rainfall anomalies of ONDJ/DJF/SON months, the bar represents seasonal rainfall anomalies, the dotted line and solid line represents linear trends of precipitation indices for the Period of 1981-2017.

\subsection{MK trend analysis of annual and seasonal rainfall}

The results of the MK-trend test 9 out of 13 stations showed an increasing trend of annual rainfall. From these Arjo, Jimma and Limugenet stations are statistically significant. The significant increasing trend of Kiremt rainfall is seen at Arjo. Dembidolo and Limugenet and decreasing at Gore. Belg, rainfall shows an increasing significant trend only in Ayira (bold values in Table 1). This result is line with the studies conducted by Gummadi et al.(2017) and Gedefaw et al.(2019). Bega season trend was not done by previous studies, positive trends at 9 stations significant at Arjo and Gatira. Spatial decreasing trends were recognized for the most parts of the region in DJF as seen in figure 3 and figure 4.

Table 1: MK- Test and Sen's Slope of Annual and Seasonal Total Rainfall in Western Oromia (1981 to 2017).

\begin{tabular}{|c|c|c|c|c|c|c|c|c|}
\hline \multirow{2}{*}{ Station } & \multicolumn{2}{|c|}{ Belg season } & \multicolumn{2}{|c|}{ Kiremt season } & \multicolumn{2}{|c|}{ Bega season } & \multicolumn{2}{|l|}{ Annual } \\
\hline & $\mathrm{Z}_{\mathrm{MK}}$ & Slope & $\mathrm{Z}_{\mathrm{MK}}$ & Slope & $\mathrm{Z}_{\mathrm{MK}}$ & Slope & $\mathrm{Z}_{\mathrm{MK}}$ test & Slope \\
\hline Arjo & 1.44 & 8.36 & 3.47 & 21.06 & $1.82 *$ & 6.83 & 3.34 & 33.75 \\
\hline Shmbu & -0.395 & -0.976 & -1.509 & -4.707 & -0.467 & -0.914 & -1.473 & -7.158 \\
\hline Nekemte & 0.956 & 4.278 & 0.47 & 2.802 & 0.664 & 1.22 & 1.25 & 6.934 \\
\hline Ayira & 2.021 & 5.308 & -0.34 & -1.297 & -1.14 & -2.079 & -0.46 & -2.919 \\
\hline Ghimbi & 1.297 & 3.089 & 0.308 & 0.562 & -0.6 & -1.116 & 0.697 & 4.31 \\
\hline Dembidolo & 1.563 & 3.973 & 1.96 & 8.854 & -0.918 & -1.89 & 1.563 & 11.198 \\
\hline Bedele & 0.995 & 1.625 & 0.668 & 2.716 & 0.571 & 1.296 & 1.093 & 4.815 \\
\hline Gore & 0.421 & 0.687 & -2.124 & -7.356 & 0.308 & 0.717 & -1.216 & -6.881 \\
\hline Chira & -0.918 & -1.792 & -0.068 & -0.216 & 0.578 & 0.76 & -0.102 & -0.421 \\
\hline Jimma & 0.665 & 1.336 & 0.989 & 2.572 & 1.087 & 1.356 & $1.64^{*}$ & 6.126 \\
\hline Limugenet & -0.172 & -0.569 & $1.89^{*}$ & 10.527 & 0.34 & 0.415 & $1.80^{*}$ & 11.148 \\
\hline Sekoru & 0.31 & 0.669 & -0.73 & -1.261 & 0.86 & 1.26 & -0.37 & -1.509 \\
\hline Gatira & 0.308 & 0.812 & 0.697 & 1.92 & $1.64 *$ & 3.77 & 1.22 & 6.18 \\
\hline
\end{tabular}

$\mathrm{Z}_{\mathrm{MK}}$ (Mann-Kendall test), Slope (Sen's slope) (mm)/ (annual /season), Bold* = significant at Significance level 10\%. 


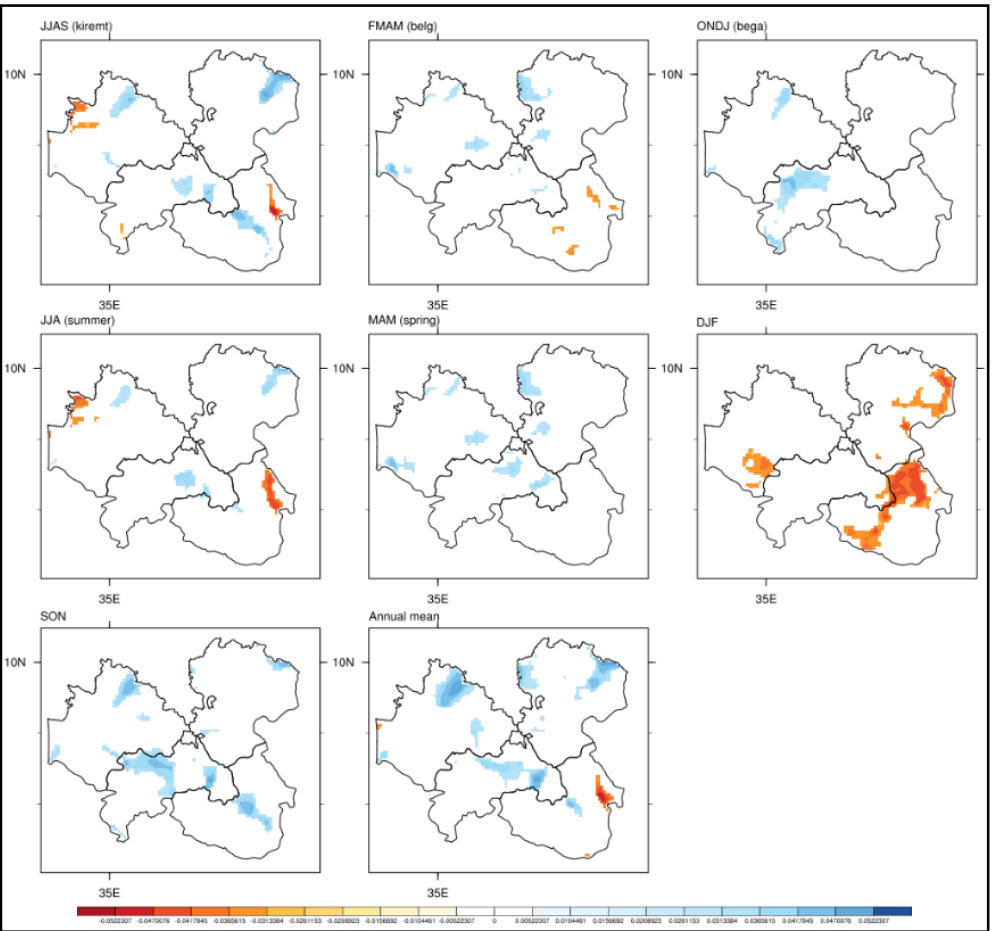

Fig. 4: The Spatial Patterns of Trends of Seasonal Standardized Anomaly Index (SAI) Of Rainfall in the Period of 1981-2017.

\subsection{Correlation of seasonal rainfall to SST, PSI and SLP}

The relationship between rainfall to SST SLP, and PSI were examined by Pearson correlation at significance level of 5\%, and mapped for summer and spring seasons.

\subsubsection{Relationships kiremt (summer) rainfall with SST and PSI indices}

Seasonal correlations between regional rainfalls and different SST indices have linkage. To determine the influence of SST on Kiremt/summer rainfall, different indices such as El Niño Southern Oscillation (ENSO), Pacific Decadal Oscillation (PDO), Atlantic Multi decadal Oscillation (AMO) and DMI (IOD) of Indian Ocean Dipole were analyzed. It was identified that the association with all Niño regions which are used as a measure of ENSO (Niño 1.2, Niño 3, Niño 3.4 and Niño 4) and PDO, both showed negative correlation. This means Kiremt rainfall in Western Oromia expected to increase when La Nina condition happened and the effect of El Nino was decreasing rainfall in the region. On the contrary, DMI (IOD) and AMO showed positive association over the region. Indian Ocean Dipole and AMO phase has an increasing effect and decreased during negative IOD and AMO event (Figure 5). All Nino regions Niño 1.2, Niño 3, Niño 3.4 and Niño 4 showed similar correlation with kiremt rainfall. The findings agree with recent studies on ENSO (Niño3.4) and IOD (Shanko, 1998; Segele, 2009; Daniel, 2019). Whereas, PSI to rainfall correlation showed significant positive spatial association over the western part (West Wolega and Illubabor) and showed no relation to the East (Jimma \& East wollega).

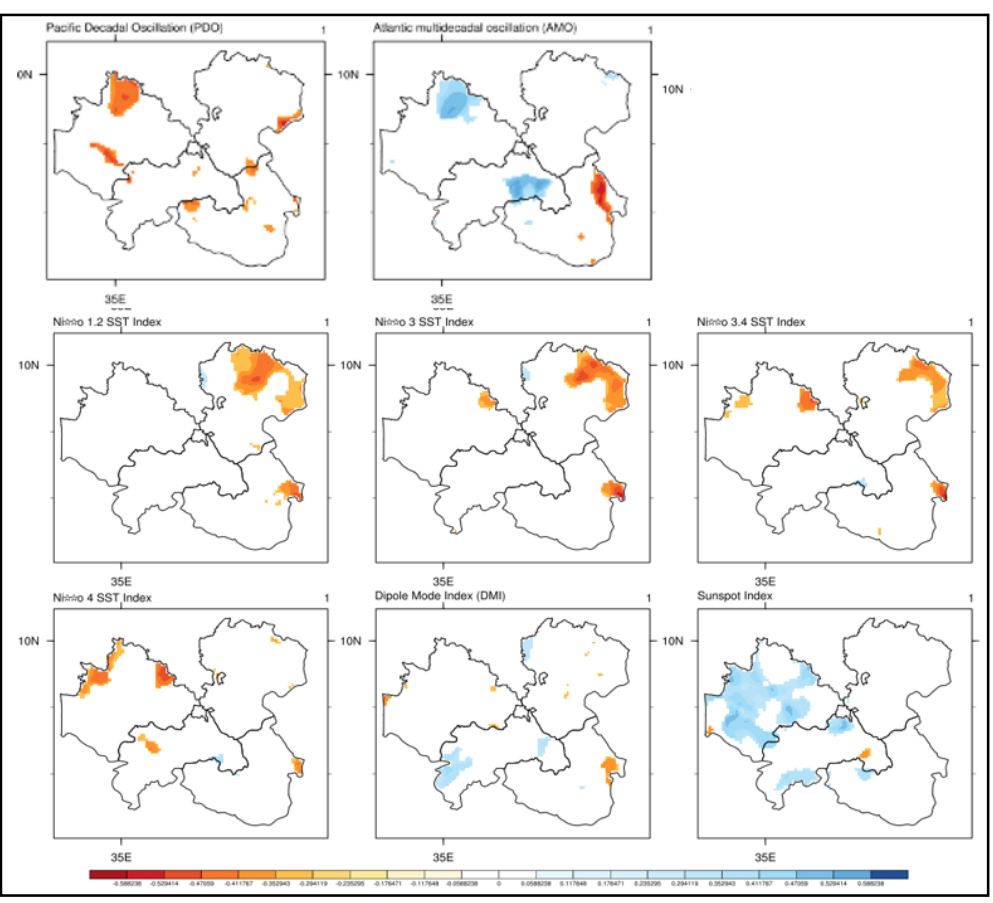


Fig. 5: Correlation of Kiremt (Summer) Rainfall with SST and PSI Indices: Pacific Decadal Oscillation (PDO), Atlantic Multi decadal Oscillation (AMO) ENSO (Nino1.2, Nino3, Nino3.4 and 4), Dipole Mode Index (DMI) and Sunspot (SPI) indices.

\subsubsection{Relationships Belg (spring) rainfall with SST and PSI indices}

The correlation between Belg rainfall data and oceanic indices showed weak spatial statistical association as compared to Kiremt (summer). The result of the analysis indicates that spatial good negative association was found with Nino indices (Nino 1.2, Nino 3, Nino 3.4 and Nino 4) over Jimma zone. No significant correlation observed for the rest zones. Similarily,DMI and AMO show no significant spatial correlation. On the contrary, PDO showed negative association for the most parts of the region. Whereas, PSI to rainfall correlation showed significant no spatial association over the western part (West Wolega and Illubabor) and showed negative relation to the East part (Jimma \& East wollega) of the region.

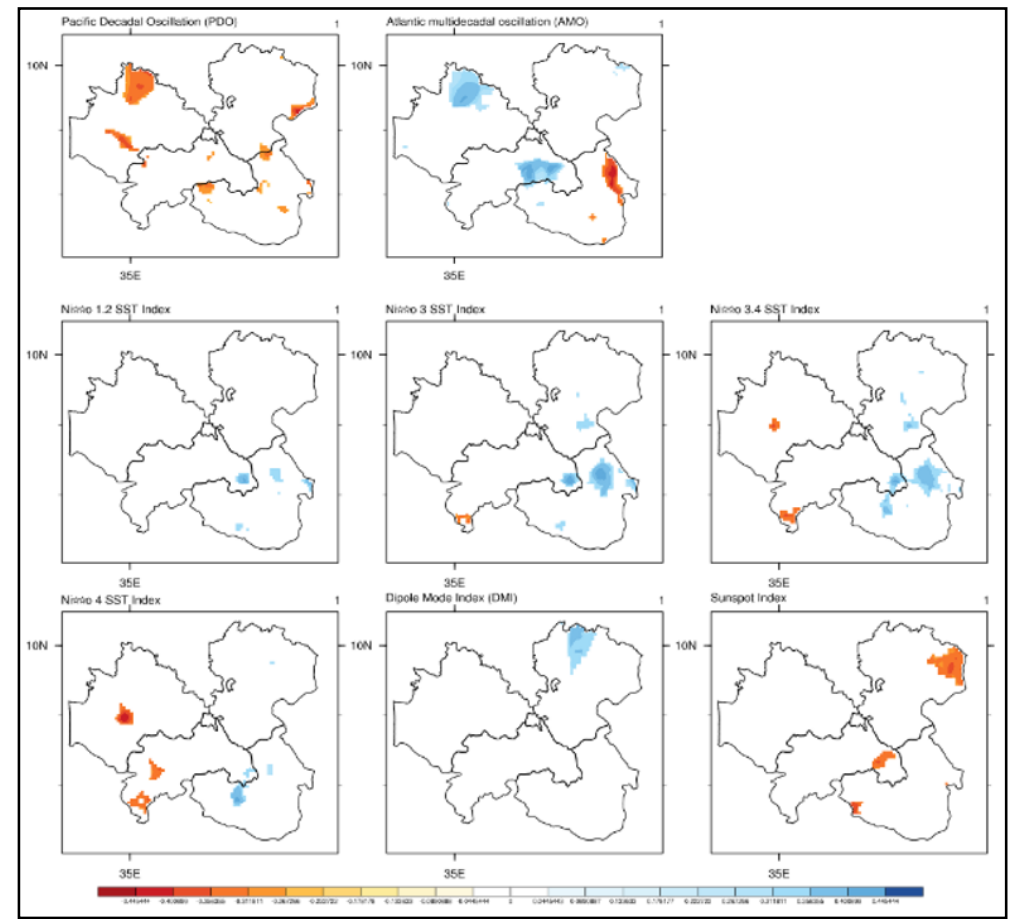

Fig. 6: Correlation of Belg (Spring) Rainfall with SST and PSI Indices: Pacific Decadal Oscillation (PDO), Atlantic Multi decadal Oscillation(AMO), ENSO indices (Nino1.2, Nino 3, Nino 3.4 and Nino4), Dipole Mode Index (DMI) and sunspot indices.

\subsection{Relationships dominant modes of SLP with seasonal rainfall over the west Oromia}

\subsubsection{Relationships of SLP with kiremt (summer) rainfall over the west Oromia}

Figure (7) shows that the correlation between Kiremt (summer) seasonal rainfall and SLP of Pacific, Atlantic TPI and Arctic oscillation. Investigation of the relationship between seasonal rainfall and SLP has revealed less spatial significance correlation signals for the study region. But the kiremt rainfall of Illubabor zone showed negative relation with SOI, NAO and AO, and the rainfall of east and west Wollega has negative correlation with TPI. Positive SOI, AO, NAO anomalies lead to rainfall deficits, whereas Belg seasonal rainfall reveled positive correlation with Normalized Tahiti (SOI) and Trans Polar Index(TPI) . This finding are agreed with study done by Yirgaw(2011) and Gissela et al. (2004) as correlation between rainfall and the southern oscillation index varies with a strong connection present only in some regions.

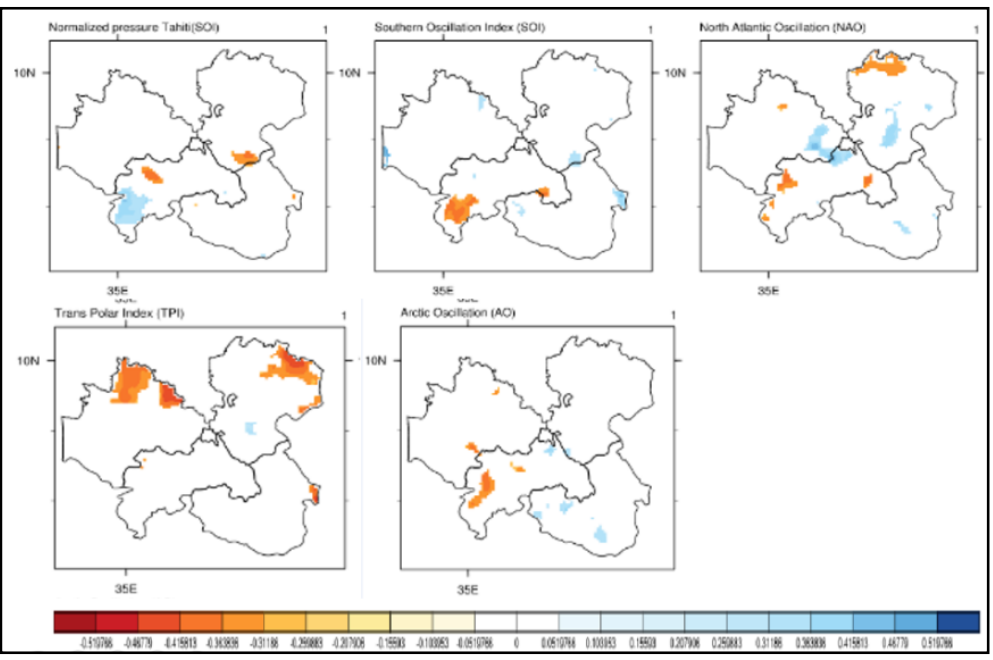

Fig. 7: Correlation of Kiremt (summer) Rainfall with SLP Indices: Normalized Pressure Tahiti (SOI), Trans Polar Index (TPI), North Atlantic Oscillation (NAO), Southern Oscillation Index (SOI) and Arctic Oscillation (AO). 


\subsubsection{Relationships of SLP with Belg (spring) Rainfall over the west Oromia}

In other words, SLP had no significant spatial the most influence on precipitation of the studied area. However, Normalized Pressure Tahiti (SOI), Trans Polar Index (TPI) showed positive correlation with Belg rainfall across Jimma and west Wollega zones. The correlation between North Atlantic Oscillation (NAO), Southern Oscillation Index (SOI) and Arctic Oscillation (AO) with Belg rainfall is low variable in space ranging from no to negative correlation over Western Oromia (Figure 8). The correlation between rainfall and Belg season rainfall is weak. General, previous study Ayele et al. (2019) identified the negative influence of NAO on Belg rainfall in the region.

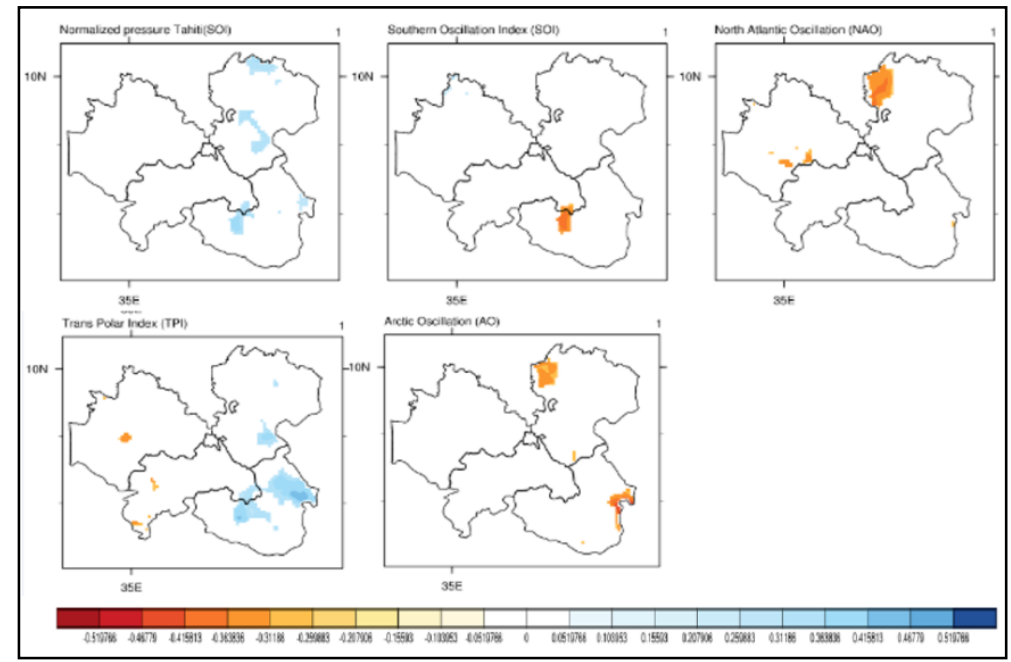

Fig. 8: Correlation of Belg (Spring) Rainfall with SLP Indices: Normalized Pressure Tahiti (SOI), Trans Polar Index (TPI), North Atlantic Oscillation (NAO), Southern Oscillation Index (SOI) and Arctic Oscillation (AO).

\section{Conclusion}

Associations between regional climates and its potential drivers are important in understanding the rainfall regime of a given area. The MK-trend test showed an increasing trend change in annual and seasonal rainfall. This may be a signal of climate change impact in the region. Seasonal rainfall relationships with SSTs show: the Niño regions indices and PDO showed negative correlation, but DMI and AMO showed positive association over the region correlation with kiremt rainfall. Nino region indices, DMI and AMO showed positive correlation for belg rainfall. On the contrary, PDO showed negative association for the most parts of the region. PSI to kiremt/Belg rainfall correlation showed significant positive/Negative spatial association over the western part (West Wolega and Illubabor) / the East part (Jimma \& East wollega) of the region. The relationship between seasonal rainfall and SLP has revealed less spatial significance correlation signals for the study region. But the kiremt rainfall of Illubabor zone showed negative relation with SOI, NAO and AO, and the rainfall of east and west Wollega has negative correlation with TPI. Belg season rainfall showed positive correlation with Normalized pressure Tahiti (SOI) and TPI.

\section{Acknowledgement}

We are grateful to the Addis Ababa University, Institute of Geophysics, Space Science and Astronomy (IGSSA) for providing funding and technical support. We are also grateful to Mr. Gemechu Raga for collaborative assistance and National Meteorological Agency (NMA) for providing meteorological data.

\section{References}

[1] Ayele et al. (2020) Seasonall Rainfall Variablity in Ethiopia and Its Long-Term Link to Global Sea Surface. Water 12(55); doi: $10.33900 / w 12010055$.

[2] Admassu, S. (2006) Analysis of rainfall trend in Ethiopia. Eth J.Sci \& Technol.3 (2), 15-30.

[3] Bezu, A.(2020) Analyzing Impacts of Climate variability and Changes in Ethiopia: A review. American Journal of Modern Energy, 6(3), 65-76.

[4] Daba, M. H. (2018). Agro Climatic Characterization in the Selected Woredas of Western Oromia, Ethiopia. Journal of Earth Science \& Climatic Change, Vol 9(3). https://doi.org/10.4172/2157-7617.1000455.

[5] Daniel G, D. R. (2019). Does the IOD Independently Influence Seasonal Monsoon Patterns in Northern Ethiopia? Atmosphere, 10, 432. https://doi.org/10.3390/atmos10080432.

[6] Diro G., G. D. (2011). Teleconnections between Ethiopian summer rainfall and sea surface temperature. Part II. Seasonal forecasting. Clim. Dyn., 37, 121-131. https://doi.org/10.1007/s00382-010-0896-x.

[7] Egor, A. O. (2015). Inter-Annual Variability of Rainfall in Some States of Southern Nigeria. International Journal of Scientific \& Technology Research (4), 2277-8616.

[8] Fahey, D. S. (2017). Physical drivers of climate in: Climate Science Special Report: Fourth National Climate Assessment, Volume I. Washington, DC, USA: U.S. Global Change Research Program.

[9] Friederike E L Otto, P. W. (2018). Anthropogenic influence on the drivers of the Western Cape drought 2015-2017. Environ. Res. Lett. 13, 124010. https://doi.org/10.1088/1748-9326/aae9f9.

[10] Gissila, T. B. (2004). Seasonal forecasting of the Ethiopian summer rains. Int. J. Climatol, 24, 1345-1358. https://doi.org/10.1002/joc.1078.

[11] Golian, H. R. (2015). Assessing the correlation between climate signals and monthly mean and extreme precipitation and discharge of Golestan Dam Watershed. Eart Sci. Res. J. Vol. 19, No. 1, 65 - 72. https://doi.org/10.15446/esrj.v19n1.40996.

[12] Gummadi et al.(2017) Spatio-temporal variability and trends of precipitation and extreme rainfall events in Ethiopiain1980-2010. Theoretical and Applied Climatology. https://doi.org/10.1007/s00704-017-2340-1. 
[13] Jestinos Mzezewa, T. M. (2010). Characterisation of rainfall at a semi-arid ecotope in the Limpopo Province (South Africa) and its implications for sustainable crop production. Water SA, vol.36 n.1, vol.36 n.1. https://doi.org/10.4314/wsa.v36i1.50903.

[14] Nath, M. A. (2015). Study on Rainfall Probability Analysis at Allahabad District of Uttar Pradesh. Journal of Biology, Agriculture and Healthcare, Vol.5, No.11.

[15] Segele Z., L. P. (2009). Large-scale atmospheric circulation and global sea surface temperature associations with Horn of Africa June-September rainfall. Int. J. Climatol., 29, 1075-1100. https://doi.org/10.1002/joc.1751.

[16] Shanko, D. \&. (1998). The effects of the Southwest Indian Ocean tropical cyclones on Ethiopian drought. Int. J. Climatol., 18, 1373-1388. https://doi.org/10.1002/(SICI)1097-0088(1998100)18:12<1373::AID-JOC313>3.0.CO;2-K

[17] Viste et al (2012) Recent Drought and Precipitation tendencies in Ethiopia. Theoretical and Applied Climatology.www.sspringerlink.com/content/r84166851504xx2x2/.

[18] Willems, C. O. (2015). Spatial and temporal variability of rainfall in the Nile Basin. Hydrol. Earth Syst. Sci., 19, 2227-2246. https://doi.org/10.5194/hess-19-2227-2015.

[19] Yirgaw, D. G. (2011). Climate variability in the drought prone regions of Northern Ethiopia. Göteborg: Göteborg University, Sweden. 